REVISTA CHILENA DE LITERATURA

Noviembre 2009, Número 75, 331 - 341

\title{
V. RESEÑAS
}

Ignacio Arellano y José Antonio Rodríguez Garrido (eds.)

El teatro en la Hispanoamérica colonial

Navarra/Madrid/Frankfurt am Main: Universidad de Navarra-Iberoamericana-Vervuert, 2008.

El teatro en la Hispanoamérica colonial -décima entrega de la reconocida Biblioteca Indiana de Iberoamericana-Vervuert, bajo la edición de los académicos Ignacio Arellano y José Antonio Rodríguez Garrido-reúne trabajos escritos por investigadores de América y Europa, en el marco de un congreso realizado en la ciudad de Lima entre el 5 y el 7 de abril de 2006, y organizado por el Instituto Riva-Agüero de la Pontificia Universidad Católica del Perú y el GRISO de la Universidad de Navarra, bajo el título El teatro de Hispanoamérica Colonial (siglos XVI-XVIII): Textos, prácticas escénicas y contextos de representación ${ }^{1}$.

El hecho de que el volumen está conformado por un número considerable de estudios -veintitrés en total, cada uno con su propia aproximación al teatro hispanoamericano colonial-dificulta un enfoque global que dé cuenta de todos los aspectos relevantes de la obra. El mismo término colonial es aprovechado en toda su complejidad para incluir aportes de variada clase, extensión y nivel de profundidad. Mientras que algunos trabajos se centran los aspectos de producción de las obras y sus antecedentes (peninsulares, prehispánicos), otros consideran la labor evangelizadora del teatro, su función social, política y educativa, el fenómeno de la representación o bien aspectos de edición, entre otros. Parece conveniente, entonces, esbozar una breve descripción de cada una de las entregas.

Como se puede leer en la presentación que hacen los mismos editores, el primer conjunto de trabajos gira en torno a la producción teatral escolar jesuita. Julio Alonso Asenjo analiza la apoteosis o exaltación de valores en el Coloquio a lo pastoril de Cigorondo (1598), obra compleja y con una marcada función ejemplar, que a través del uso de figuras de la poesía bucólica (Alexis, Dafnis), refleja una interesante mezcla de tradiciones, destacándose la autoridad del mundo clásico y la inclusión de la música. A continuación, Pedro Guibovich Pérez entrega un completísimo panorama del teatro jesuita en el virreinato del Perú -al servicio de "la causa de Dios y de los hombres" (37)- y su estrecho vínculo con la sociedad mediante variadas funciones (loa de los poderosos, el realce de las fiestas religiosas, la propaganda a la Compañía y la función didáctica,

${ }^{1}$ Esta reseña se realizó con el apoyo de una beca doctoral Conicyt, programa de Doctorado en Literatura, Universidad de Chile. 
transmisora de valores). Además, se analizan aspectos como el lugar de la representación o la presencia de la música. Por otra parte, María Palomar Verea trabaja con dos comedias sobre la conversión de San Francisco de Borja (una de ellas escrita en México a mediados del siglo XVII, Comedia de San Francisco de Borja, y la otra atribuida a Calderón, El gran duque de Gandía), analizando la influencia e importancia del género hagiográfico en el contexto popular y la disminución de elementos sobrenaturales en el siglo XVI.

Sigue el trabajo de Margaret Greer, que también revisa dos obras: desarrolla un análisis de la caza como elemento alegórico y con función política en una obra de Calderón de la Barca y otra de González de Eslava.

En un conjunto dedicado al teatro escrito en lengua indígena, encontramos en primer lugar una aproximación de Claudia Parodi a los textos indianizados, a través de la figura de Bartolomé de Alva Ixtlixóchitl y su traducción de Calderón al náhuatl. La obra del autor novohispano es presentada como una combinación de elementos provenientes del teatro de evangelización, el teatro criollo en castellano -destacándose la rama del teatro humanista jesuita-y el teatro peninsular español, y donde el mundo europeo es adaptado al contexto americano de Alva. En segundo lugar, Beatriz Aracil Varón se ocupa de la adaptación del teatro peninsular al contexto americano a partir esta vez de una obra en lengua quechua, Usca Paucar, que reelabora la historia del pacto con el demonio con un fin moralizador.

Sigue una sección conformada por trabajos que se enfocan en los actores y prácticas escénicas, en palabras de los editores. Muy atractivo es el estudio que hace Pilar Latasa de la difícil situación y mala reputación de las actrices en la colonia; para ello, revisa la figura de la actriz María de Torres Tamayo y su pleito contra Diego Muñoz, en el contexto de una promesa matrimonial en el Perú. Luego, los espacios -no entendidos ya como mero "receptáculo de acciones" o "elemento decorativo"- son analizados por Dalmacio Rodríguez Hernández en La verdad sospechosa de Juan Ruiz de Alarcón. Se establecen aquí importantes vínculos entre los espacios (simbólicos) en las obras y las conductas humanas que se desarrollan en ellos, ayudando a su comprensión y justificación, y operando al mismo tiempo como otorgadores de identidad social. También Susana Hernández Araico trabaja los espacios, visualizados o verbalizados, esta vez en Los empeños de una casa de Sor Juana Inés de la Cruz, destacando cómo toda acción gira en torno al espacio de la casa. Se hacen además importantes comentarios acerca de la influencia que la situación y el estudio del espacio en la edición de textos ejercen en la configuración del escenario.

El teatro de Sor Juana también es revisado por Carmela Zanelli, en un trabajo titulado "De palestras, disputas y travestimos", donde aborda diferentes aspectos de Los empeños de una casa, destacándose la representación de la cultura americana.

Encabezando un nuevo conjunto, dedicado a los modelos teatrales, Eduardo Hopkins Rodríguez se centra en la participación y reelaboración del modelo trágico en el teatro colonial peruano, considerando factores como la necesidad de representar lo horrible del mundo, propia de la Contrarreforma y el Barroco, y el prestigio de los modelos clásicos, refiriéndose particularmente a la influencia de Séneca en la Europa de los siglos XVI y XVII y su visión trágica predominante en los textos considerados (Amar su propia 
muerte, La Rodoguna y Ollantay). El trabajo de José Rodríguez Garrido analiza el teatro de Pedro de Peralta y Barnuevo, autor con múltiples conocimientos; hace énfasis en el vínculo discurso-poder, el intento por participar de este último a través de los escritos y la legitimación de la memoria criolla. De interés resulta también el desarrollo de los modelos teatrales y el análisis del elemento musical y su vínculo con los aspectos de la sociedad en que tiene lugar, en una combinación -como bien dice el título- de ópera, tragedia y comedia mitológica.

Muy novedoso - aunque algo breve- resulta "Fantasmas en el convento", trabajo en que Frederick Luciani analiza una máscara representada en el convento de San Jerónimo en la Ciudad de México (1756) con motivo de la visita del virrey, cuyo asunto gira en torno a las travesuras de una niña en el convento, y es representada por las mismas alumnas. Luciani hace referencia a variados aspectos del contexto de producción de la obra: por una parte, menciona la compleja situación de las muchachas y la dominante jerarquía en los conventos, pero también considera la función instrumental del teatro, en este caso, informativa.

A continuación encontramos un bloque de trabajos dedicado a la edición e investigación de la producción teatral en la Audiencia de Charcas. Andrés Eichmann Oehrli entrega un interesante informe de su trabajo de edición de los testimonios manuscritos ubicados en la colección musical del Archivo y Biblioteca Nacionales de Bolivia, con una descripción de los textos encontrados. Se destaca el dificultoso trabajo con partituras y particelas -una vez más vemos aquí el estrecho vínculo entre música y teatro en la colonia- en el intento por establecer el texto de las obras a partir de fragmentos. El mismo corpus es abordado por Miguel Zugasti, quien, tras una descripción del trabajo de Arellano y Eichmann, se centra en dos loas de fray Juan de la Torre, representadas para la entrada del virrey en Potosí en 1716; descripciones como la de la Aclamación festiva nos permiten conocer todo el movimiento y aparataje que una representación con estas características implicaba. Por su parte, Ignacio Arellano analiza con mucha claridad el elemento cómico en los siete entremeses completos y dos reconstruidos del corpus de Charcas: situaciones cómicas, tipos cómicos, medios escénicos y la palabra cómica; dentro de esta última, posee especial atractivo la efectiva imitación del habla de los diferentes grupos locales.

Sigue un estudio de Carlos García-Bedoya centrado en la reconstrucción y reinterpretación del pasado del Perú - particularmente, el fin de Atahualpa- en dos obras dramáticas, la Tragedia del fin de Atahualpa y La conquista del Perú. Este trabajo nos muestra las múltiples reelaboraciones que puede tener un solo referente, frecuentemente con influencia de su contexto de producción. En la misma línea del teatro colonial peruano y sus antecedentes, Ari Zighelboim revisa la obra Ollantay en función de la historia de su transmisión, descartando la posibilidad de que se trate de una obra con origen en un texto prehispánico y vinculándola más bien al incaísmo criollo.

Margarita Peña se centra en La lealtad americana, de Fernando Gávila, obra que aborda el tema de la piratería, cumpliendo con los preceptos neoclásicos. A través de ella, Peña analiza la "relación entre el arte y poder a través del mecenazgo teatral" (393). 
En un trabajo que se aleja en carácter de los restantes de este volumen, Dalia Hernández Reyes entrega un particular estudio de la función que cumplen las gacetas y diarios en el siglo XVIII en Nueva España en la transmisión del teatro, sus debates y preceptos. En este contexto, la autora menciona -considerando el enfrentamiento entre defensores del antiguo estilo y el nuevo- una serie de concursos teatrales llevados a cabo alrededor del 1800 por el Diario de México, cuyos registros dan cuenta de la situación teatral novohispana en esta época y el valor que se confiere al sainete a pesar de tratarse de un "género menor".

En "Lope de Vega en los Andes”, Milena Cáceres da a conocer cómo algunos textos del teatro aurisecular se han mantenido en la tradición de ciertas localidades andinas del Perú, especialmente en la celebración de fiestas religiosas con la participación de todo el pueblo. El trabajo se centra en el enfrentamiento entre moros y cristianos a través de las figuras de Garcilaso y Tarfé, su desarrollo por parte de Lope de Vega y su reelaboración por la comunidad de Huamantanga. Gonzalo Santoja Gómez ofrece un repertorio de autores peninsulares que de una manera u otra estuvieron vinculados a América, deteniéndose en la figura de Tirso de Molina y su viaje a América.

Cierra el volumen el análisis de la leyenda de la "cueva de Salamanca" y el pacto con el demonio, por Celsa Carmen García Valdés. La investigadora se centra en la pervivencia de esta leyenda en la tradición oral de numerosas localidades y en algunas reelaboraciones literarias, entre ellas la de Juan Ruiz de Alarcón.

El teatro en la Hispanoamérica colonial constituye, en suma, una entrega bastante heterogénea y variable en sus grados de profundidad, que permite conocer los múltiples caminos que siguen actualmente los estudios teatrales de Hispanoamérica. Extrañamos en el volumen, en todo caso, el trabajo de Laura Bass, al cual aluden los editores en la presentación.

El volumen puede ser abordado desde la lectura separada de los trabajos individuales, según el interés del lector, pero también en su totalidad, como un amplio panorama del teatro colonial (y todo lo que este nombre implica, con sus virtudes y defectos) hispanoamericano, que podría resultar de gran ayuda a un lector que se inicia en este género, ofreciéndole numerosas posibilidades de análisis. Por otra parte, merece una mención aparte el aparato bibliográfico: cada uno de los trabajos entrega su lista de referencias, lo cual se transforma en una utilísima guía.

Nos encontramos, en consecuencia, frente a un valioso aporte al estudio de la literatura y teatro coloniales en Hispanoamérica, así como a la historia y muchos otros aspectos del período. Como los editores del volumen señalan, cabe esperar "que algunos núcleos temáticos desarrollados [...] puedan convertirse en motivo independiente de nuevos congresos y nuevos libros" (10).

María José Brañes

Pontificia Universidad Católica de Chile mjbranes@uc.cl 